\title{
Antifungal activity of the aqueous and hydro-alcoholic extracts of Terminalia superba Engl. on the in vitro growth of clinical isolates of pathogenic fungi
}

\author{
Marcel G. Ahon ${ }^{1}$, Joel M. Akapo-Akue ${ }^{1}$, Mathieu A. Kra ${ }^{1}$, Jacques B. Ackah ${ }^{1}$, \\ Noel G. Zirihi' ${ }^{2}$, Joseph A. Djaman ${ }^{1,3^{*}}$ \\ ${ }^{1}$ Laboratoire de Pharmacodynamie, UFR Biosciences, Université de Cocody, 22 BP 582 \\ Abidjan 22 \\ ${ }^{2}$ Laboratoire de Botanique, UFR Biosciences, Université de Cocody, 22 BP 582 Abidjan 22 \\ ${ }^{3}$ Département de Biochimie, Institut Pasteur de Côte d'Ivoire, 01 BP 490 Abidjan 01 \\ * Prof Dr. Joseph DJAMAN, 01 BP 490 Abidjan 01, Tel/Fax 225224444 73, \\ E-mail: djamanj@yahoo.fr
}

\begin{abstract}
In Côte d'Ivoire as elsewhere in Africa, Terminalia superba is generally used in traditional medicine to treat bacterial, fungal and viral infections. Given the importance of this plant, in this study, the antifungal activity of two extracts (aqueous and hydro-alcoholic) of Terminalia superba was evaluated on the in vitro growth of four clinical isolates of pathogenic fungi (Candida albicans, Aspergillus fumigatus, Cryptococcus neoformans, and Trichophyton mentagrophytes). The antifungal tests were performed by seeding 1,000 cells of each isolate on Sabouraud agar medium by the method of double dilution in inclined tube. Both extracts were active on different strains tested in a dose-response relationship. However, the hydroalcoholic extract (XO) was four to eight times more effective than the aqueous extract (Xaq) (4 times effective against $A$. fumigatus and $\mathrm{C}$. neoformans, but 8 times against T. mentagrophytes). The phytochemical screening revealed the presence of polyterpens, polyphenols, flavonoids, tannins catechic, alkaloids and saponins.
\end{abstract}

Keywords: Antifungal activity, clinical pathogenic fungi, Terminalia superba, Côte d'Ivoire

\section{INTRODUCTION}

Plants still play a major role in the lives of people in different regions of sub-Saharan Africa, both in food and therapeutic (Hutchings et al., 1996; Kameswara et al., 2000; Kamtchouing, 2006). For example, the fruit of Thaumatoccocus danielii, used in traditional medicine contains a protein substance five thousand times sweeter than sugar cane. The rainforest is still undoubtedly a "genetical granary" in which the potential for both natural science research and in medicine (Anonyme, 1978) is not fully explored. Among the many families and species of plants used for their therapeutic properties include the family Combretaceae. It exists in the form of trees, shrubs, or lianas Their leaves are simple, without stipules, alternate, and opposite, sub opposite or verticillate. Their inflorescences are spikes or umbels and flowers are variable in size. Finally, their fruits are often vane (Adjanohoun et Aké-Assi, 1979).

Several taxa of this family are widely used for medicinal purposes in sub-Saharan Africa in general and especially in Côte d'Ivoire in the treatment of various diseases (Ionela and Ion, 2007). The Ivorian forest contains about 49 species of Combretaceae of which Terminalia superba, is found in thick rainforest zone. It is used in traditional medicine to treat many bacterial infections, fungal and viral (Van Wyk et al., 1997; McGaw et al., 2001). In Côte d'Ivoire, the bark of this plant is used to eradicate intestinal worms and treat gastrointestinal disorders such as enteritis, abdominal pain, diarrhea, fever, headache, conjunctivitis (Adjanohoun et Aké-Assi, 1979). In the Southwest, the bark of $T$. Superba, called "tree of malaria" is used by "Kroumen" (ethnic group in this region) in the treatment of malaria (Anonyme, 1978).

Given the many excellent anti-infective results obtained with this plant, this study was to evaluate the antifungal activity of aqueous and the hydro alcoholic extracts on in vitro growth of four "strains" pathogenic fungal and to determine the chemical composition of each extract of $T$. superba. 


\section{MATERIALS AND METHODS}

Preparation of extracts of Terminalia superba: The bark of $T$. superba has been collected, cut and dried. After drying, the plant materials were finely ground in an electric grinder (IKA Labortechnik). One hundred grams of powdered bark were added to one liter (1L) of solvent (distilled water or ethanol-water, v/v 70/30) and then mixed in a blender. The homogenate obtained was first centrifuged in a square of fabric, and then respectively filtered twice through cotton wool and once on Whatman paper 3MM. The filtrate obtained was concentrated using a rotary evaporator Büchi type at a temperature of $60^{\circ} \mathrm{C}$. The hydro alcoholic extract was evaporated to dryness, while the aqueous extract was concentrated and lyophilized (Burkill, 1985). The aqueous extract was called $X_{a q}$ and the hydroalcoholic extract $X_{0}$ Both extracts were tested separately on the in vitro growth of four isolates of fungi.

Fungi tested: The strains of fungi (C. albicans, $A$. fumigatus, $C$. neoformans and $T$. mentagrophytes) used in this study were provided by the Laboratory of Mycology of the Faculty of Medical Sciences of the University of Cocody-Abidjan (Côte d'Ivoire). These germs have been isolated from patients from the infectious Diseases Department of Hospital of Treichville (Abidjan).

C. albicans is part of the normal flora (gastrointestinal and reproductive tract of women). However, it becomes pathogenic when the immune system fails. The generalized infection caused by this yeast in individuals severely immuno-compromised often lead to death (Ahmadi et al., 2009). As C. neoformans, it is responsible for most of human cryptococcosis, the most common is the meningo-encephalitis. This species also causes serious bloodstream infections in sub acute evolution where untreated cases could be fatal (Gentilini et al., 1993).

A. fumigatus is a ubiquitous filamentous fungus always present found everywhere in nature (Bouchet, 1984; Chouvala, 1984; Gentilini et al., 1993). It is responsible for $80-90 \%$ of humans aspergillosis, the most common are bronchopulmonary aspergillosis. This species is known to be particularly pernicious and "rebel" to therapy. Finally T. mentagrophytes is a cosmopolitan filamentous fungus (Chouvala, 1984; Gentilini et al., 1993) whose growth is favored by many factors including heat, humidity, poor hygiene, exaggerated taking of corticosteroids, and comorbidity. T. mentagrophytes causes ringworm.
Antimicrobial Test: The cultures of different "strains" of fungi have been carried out on Sabouraud agar (Biomerieux, 51078 Ref: 777666501). The inclusion of plant extracts in the agar was made using the method of the double dilution agar slopes (Ajello et al., 1963; Guédé-Guina et al., 1995; Zirihi et al., 2003). Both extracts (aqueous and ethanol) were tested separately. Each test series consisted of eight tubes containing the plant extract and two control tubes in which one is without a plant extract used to monitor the growth of germs, and the other germ-free tube and without plant extract was used as sterility controls to the culture medium. For the eight test tubes, concentrations of plant extract ranged from 780 to $6.09 \mu \mathrm{g} / \mathrm{mL}$ binding by a geometrical reason of $1 / 2$.

After incorporation of the extract to the agar, all ten tubes of each series were sterilized in an autoclave at $121^{\circ} \mathrm{C}$ for 15 minutes and then inclined to room temperature to allow cooling and solidification of the agar (Holt, 1975).

The inoculum was prepared from young cultures of $C$. albicans, $A$. fumigatus, $C$. neoformans (aged 48 hours of incubation) and T. mentagrophytes (aged 5 days of incubation). The stock suspension concentrated to $10^{6}$ cells $/ \mathrm{mL}$ (corresponding to a dilution $10^{\circ}$ ) was first prepared by homogenizing a colony of each fungal strain in $10 \mathrm{~mL}$ of sterilized distilled water. One milliliter of the suspension $10^{\circ}$ was transferred to $9 \mathrm{~mL}$ of sterilized distilled water to give a second suspension concentrated to $10^{5}$ cells $/ \mathrm{mL}$. For each test tube of the two series of extracts (aqueous and hydro-alcoholic), the culture was made on medium previously prepared by seeding in transverse striations (till exhausted) of $10 \mathrm{~mL}$ of the suspension $10^{-1}$. This corresponded to 1,000 cells seeded.

After incubation (at $30^{\circ} \mathrm{C}$ for 48 hours for $C$. albicans, A. fumigatus, C. neoformans and for 5 days for $T$. mentagrophytes), the colonies of each isolate were numbered by direct counting with a pen colony counter (Serial number 23382, Scinceware Bel-Art). Growth in the eight tubes of each experimental series was assessed as a percentage of survival compared to $100 \%$ survival in the control tube growth control (Pechere, 1970; Laurent et al., 1992). Treatment of experimental data was used to determine the antifungal parameters (MFC, $\mathrm{IC}_{50}$ ).

Phytochemical screening: This section of the study is to highlight the presence of chemical compounds in aqueous extracts and hydro-alcoholic extract of the bark of $T$. superba. The methods used for revealing the presence of chemical constituents are those 
conventionally used in the phytochemical screening of medicinal plants. To search for polyterpens, reagent used is that of Liebermann. Polyphenols have been detected by the reaction to ferric chloride. The reaction to cyanidin helped to highlight the flavonoids. For tannins, their presence have been detected by the Stiasny reagent. Quinone groups free or combined were highlighted through the reagent Borntraegen. The alkaloids were detected by the Dragendorff reagents or Bouchardat Valsen-Mayer. Finally, the saponins have been identified by measuring the height of foam after shaking.

Analysis results: The MFC (minimal fungicidal concentration) and $\mathrm{IC}_{50}$ (concentration for $50 \%$ inhibition) were used to evaluate the antifungal activity of different extracts. In practice, the MFC is the extract concentration in the tube, which gave $99.99 \%$ inhibition compared to the control tube growth control. As for the $\mathrm{IC}_{50}$, it is determined graphically.

To better estimate the quantity of chemical constituents in the extracts, scores ranging from 0-3 Table 1: Antifungal parameters of the extracts of Terminalia superba

\begin{tabular}{|l|l|l|l|l|}
\hline & \multicolumn{4}{l}{ Antifungal parameters } \\
\hline Pathogenic fungi & \multicolumn{2}{|l|}{ MFC $(\mu \mathrm{g} / \mathrm{mL})$} & \multicolumn{2}{l|}{ IC50 $(\mu \mathrm{g} / \mathrm{mL})$} \\
\hline & Xaq & X0 & Xaq & X0 \\
\hline C. albicans & 390.0 & 97.5 & 44.0 & 21.0 \\
\hline C. neoformans & 97.5 & 24.37 & 31.0 & 5.6 \\
\hline A. fumigatus & 390.0 & 97.5 & 37.5 & 12.0 \\
\hline T. mentagrophytes & 48.75 & 12.0 & 10.0 & 1.0 \\
\hline
\end{tabular}

In general, all sensitivity curves showed a decreasing pace with slopes more or less strong according to the extract. The $\mathrm{IC}_{50}$ values (T. mentagrophytes: $\mathrm{IC}_{50}=10$ $\square \mathrm{g} / \mathrm{mL}$ for $X_{\mathrm{aq}}$ and $\mathrm{IC}_{50}=1.0 \square \mathrm{g} / \mathrm{mL}$ for $\mathrm{X}_{0} ; A$. fumigatus: $I_{50}=37.5 \square \mathrm{g} / \mathrm{mL} \mathrm{X}$ aq and $I_{50}=12$ $\square \mathrm{g} / \mathrm{mL}$ for $X_{0}, C$. neoformans: IC ${ }_{50}=31 \square \mathrm{g} / \mathrm{mL} \mathrm{X}$ aq and $\mathrm{IC}_{50}=5.6 \square \mathrm{g} / \mathrm{mL}$ for $\left.\mathrm{X}_{0}\right)$ defined on the curves are shown in Table 1. All curves intersect the horizontal axis at different levels according to the effectiveness of each extract. With a sample $X_{0}$, the curves have slopes relatively strong, but low with the extract $\mathrm{X}_{\mathrm{aq}}$. (absent or present) have been allocated. Thus, the absence was symbolized by a score of 0 , the presence in small quantities by a score of 1 , the presence in average quantity score 2 and finally, the abundance by a score of 3 .

\section{RESULTS AND DISCUSSION}

Antifungal activity of extracts: At the end of the incubation time it was observed compared with controls, a progressive decrease in the number of colonies gradually as the concentration of extracts increased in the experimental tubes. This is observed for all series of each extract. Effective inhibitions were obtained at different concentrations of the extracts. The values of MFC (A. Fumigatus: MFC $=390 \mu \mathrm{g} / \mathrm{mL}$ and $97.5 \mu \mathrm{g} / \mathrm{mL}$; C. neoformans: MFC $=97.5 \mu \mathrm{g} / \mathrm{mL}$ and $24.37 \mu \mathrm{g} / \mathrm{mL})$ for both extracts $\left(X_{a q}\right.$ and $\left.X_{0}\right)$ are shown in Table 1. The experimental data (average of six tests) were drawn into forms of activity curves shown in Figure 1a, $1 \mathrm{~b}$.
Phytochemical screening: The phytochemical screening has enable to highlight in the extract $X_{a q}$ the presence of polyterpens, polyphenols, flavonoids, and especially of saponins. With $X_{0}$, four chemical constituents (polyterpens, polyphenols, alkaloids and saponins mainly) have been determined. No quinone compound (score 0) was detected in these two extracts. The presence of these constituents varied from one sample to another. Figure 2 shows the results of various chemical compounds in the extracts based on their quantity. 
Agric. Biol. J. N. Am., 2011, 2(2): 250-257

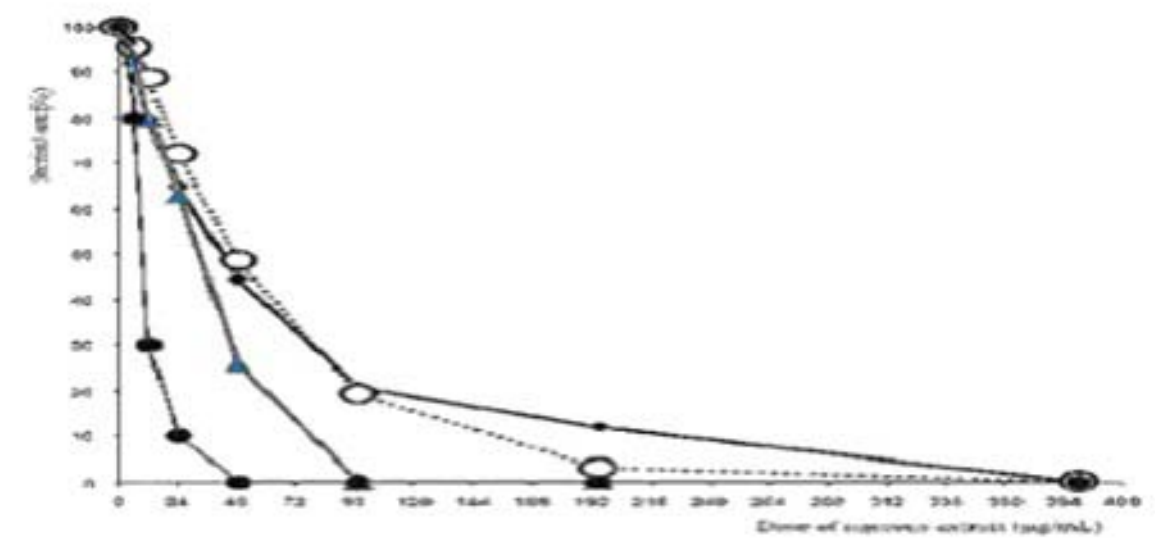

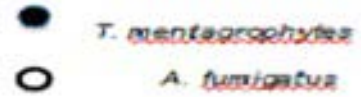

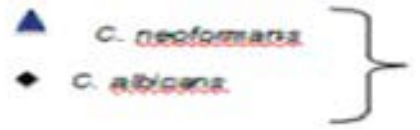

Lepends

Fig 1a: Antifungal activity of the aqueous extract of Terminalia superba 
Agric. Biol. J. N. Am., 2011, 2(2): 250-257
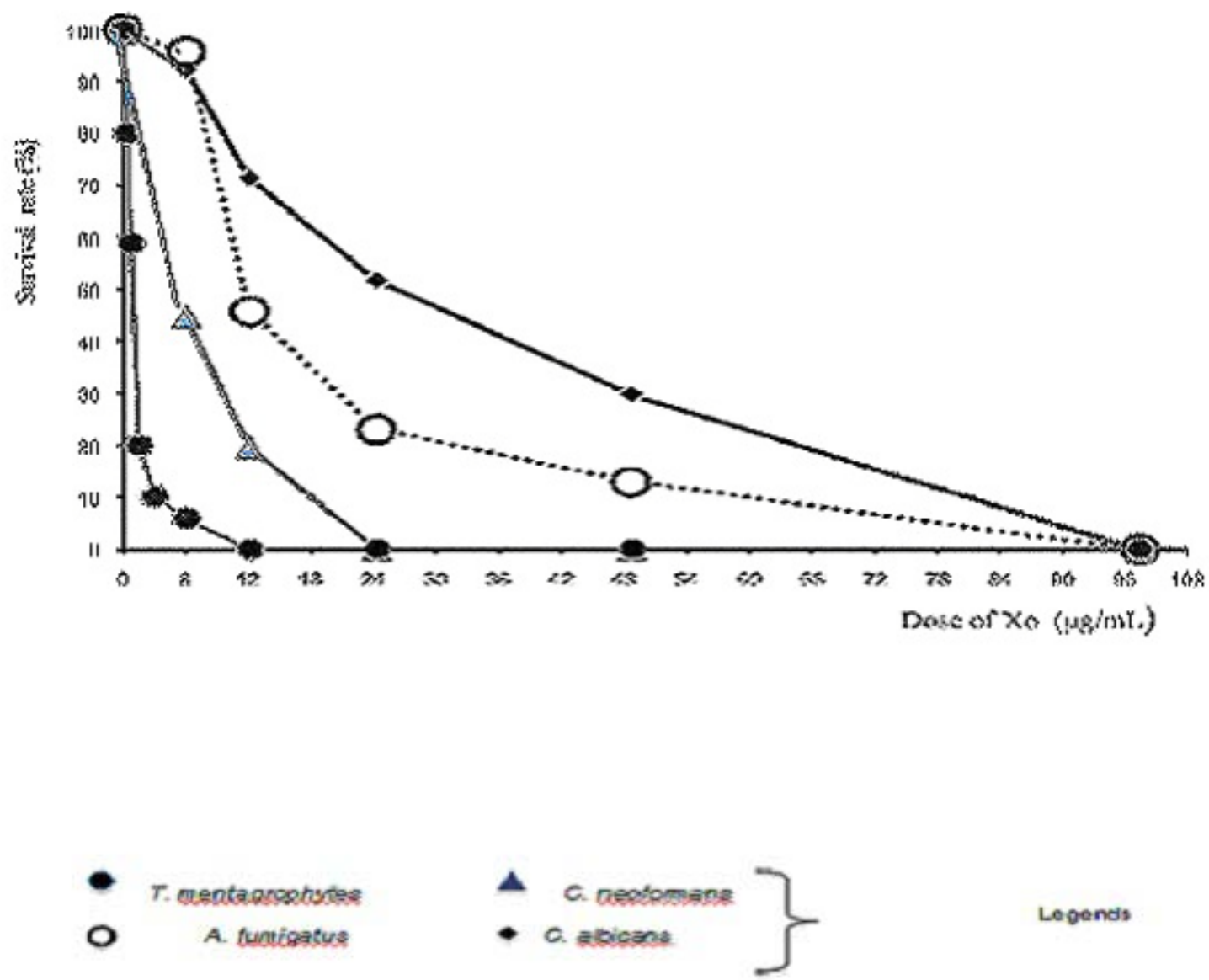

Lopends

Fig 1b: Antifungal activity of the hydro-alcoholic extract of Terminalia superba Compounds 
Agric. Biol. J. N. Am., 2011, 2(2): 250-257

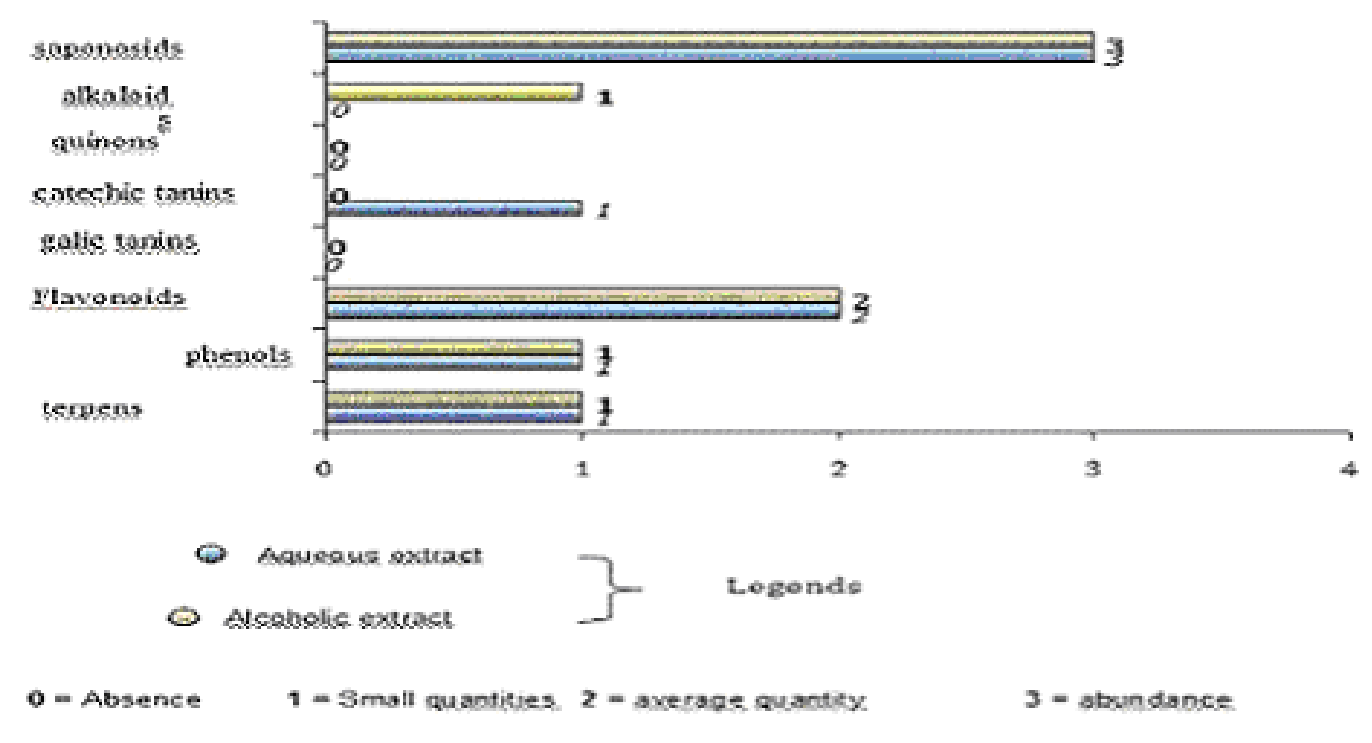

Fig 2: Chemical compounds contained in the extracts of Terminalia superba

\section{DISCUSSION}

Analysis of the antifungal activity of extracts: To verify the excellent anti-infective properties of $T$. superba in traditional medicine for which water is the solvent of choice used for the preparation of traditional recipes, the activity of aqueous total extract of this plant was first evaluated. The first results obtained with the aqueous extract guided research into the use of a second type of solvent that can better concentrate active ingredients in order to improve in vitro antifungal activity. The results obtained with both extracts showed a progressive decrease in the number of colonies depending on increase of the concentration of the extract in the tubes. Xaq and $X_{0}$ have antifungal activity against the four fungi tested in a dose-response relationship. Figures $1 \mathrm{a}$ and $1 \mathrm{~b}$ are used to compare the performance of these extracts. Thus, more the curve approaches the axis more the extract is considered active on this strain. But in general, all curves have a decreasing pace with slopes more or less strong. Depending on the slope, curves were grouped into three categories for each sample:

The curves whose slopes are very low, show a weak activity of the extract on the growth of strains.

- The curves whose slopes are moderate, illustrate an average activity of the extract on the growth of strains.
- The curves with steep slopes, show a strong activity of the extract on the growth of the strains.

Thus, for extract $\mathrm{X}_{\mathrm{aq}}$, the antifungal activity against $A$. fumigatus is low whereas on $T$. mentagrophytes this activity is strong. However, against $C$. albicans and $C$. Neoformans, antifungal activity determined is average. The aqueous extract of $T$. superba has a better antifungal activity compared to microglossia pyrifolia (MFC $=50.10^{3} \mathrm{mg} / \mathrm{mL}$ ) and Terminalia. catappa (MCF $=780 \mu \mathrm{g} / \mathrm{mL}$ ) tested by Zirihi et al., 2003 and Ackah et al., 2008 on C. albicans. Regarding the sensitivity of strains to extract $X_{0}$ of $T$. superba, the results are similar to those of $X_{a q}$. The steepest slope is that obtained with $T$. mentagrophytes followed by $C$. neoformans and $A$. fumigatus. The weakest slope is the one obtained with $C$. albicans. Indeed, the report based on the values of MFC shows that $X_{0}$ of Terminalia superba is 277 more active than $X_{0}$ of microglossia pyrifolia and 2 times more active than the hydroalcoholic extract of Terminalia catappa. Finally, the analysis of all the results showed that the extract $X_{0}$ of $T$. superba is 4 times more active than the aqueous extract $X_{a q}$ against $C$. albicans, $C$. neoformans and $A$. fumigatus, and 8 times more active against $T$. mentagrophytes. The mixture of water and ethanol is the right combination that has allowed a greater concentration of active principles in extracts of $T$. superba. The 
results of this study can therefore justify the validity of the virtues attributed to antimicrobial plant. However, in the traditional use of plants, several different aqueous extracts of different plants are used and can achieve better results in the treatment of diseases (Kamtchouing et al., 2006). The extracts may act synergistically with either one of the molecules contained in an extract potentiates the activity of another. The relevance of the study phytochemicalsorting is done about the possible compounds in the extracts to have an idea of those able to confer antimicrobial activity.

Analysis of the Phytochemical screening: Thus, considering the results of the phytochemical screening analysis, it is possible to affirm that there is an abundance of saponins in both extracts and an average proportion of flavonoids. It has been found that extract $X_{a q}$ contains 6 elements (terpens, sterols, phenols, flavonoids, tannins, saponins), while the extract $X_{0}$ contains only 5 . Although not containing tannins, this extract concentrates a small proportion of alkaloids (Burkill, 1985). It is possible that the antifungal activity is not related to catechin tannins present in $\mathrm{X}_{\mathrm{aq}}\left(\mathrm{X}_{0}\right.$ does not contain). However, given that $X_{0}$ is more active than $X_{a q}$, it is possible that the activity is linked to different types of chemical formula or identical in nature but different in conformation in the extracts. $X_{\mathrm{Aq}}$ and $\mathrm{X}_{0}$ then would contain different properties of polyphenols, polyterpens, flavonoids and saponins. According to the work of Cowan in 1999 and those of Iwu et al. (1999), and of Ionela and Ion (2007), the antimicrobial activity of flavonoids, polyphenols, polyterpens, alkaloids and saponins can be explained by the fact that they are not only capable of complexing extracellular proteins but also to break the microbial membranes causing cell death.

\section{CONCLUSION}

This study has enabled us to locate the true potential anti-microbial in general, but especially anti-fungal extracts of $T$. superba on the in vitro growth of $C$. albicans, A. fumigatus, $C$. neoformans and $T$. mentagrophytes. The results of these study have shown that aqueous extracts and hydro-alcoholic extract of $T$ superba have a dose-dependent fungicidal activity against clinical fungal isolates used and that this activity is improved with the hydroalcoholic extract, which has helped to concentrate the active ingredients. Out of the four fungal isolates tested $T$. mentagrophytes is the most sensitive to extract and the less sensitive is $C$. albicans.
In rural traditional, the use of $T$. superba as antimicrobial therapy is justified. The therapeutic qualities of this plant are related to many chemical compounds including terpens, phenols, saponins etc. that it contains. It would be desirable by a bio-guided fractionation to isolate each compound or group of compounds to identify the one, which is responsible for $T$. superba's antifungal activity.

\section{ACKNOWLEDGMENTS}

The authors are grateful to the Laboratory of Parasitology and Mycology of the Faculty of Medical Sciences of the University of Cocody-Abidjan for having provided the strains of fungi used in this study.

\section{REFERENCES}

Ackah, A.J., Kra, M.A.K., Zirihi, N.G., Guédé-Guina, F. (2008). Evaluation et essai d'optimisation de l'activité antifongique de Terminalia catappa (TEKAM3), un extrait de Combrétacée de la pharmacopée Ivoirienne. Bull. de la Soc. R. Sci. (Liège) 77: 120-136.

Adjanohoun, J.E., Aké-Assi, L (1979). Contribution au recensement des plantes médicinales de Côte d'Ivoire. Centre National et floristique, Abidjan, Côte d'Ivoire, pp 40-219.

Ahmadi, F., Ahmadi, M., Yaghmaei, B., Nejat, F., Rezaei, N., Mamishi, S (2009). Candida albicans meningitis in an infant with Noonan syndrome. Braz. J. Infect. Dis. 13: $452-453$.

Ajello, L., Georg, L.K., Kaplan, W., Kaufman, L. (1963). Laboratory manual for medical mycology. 2nd Ed. john wiley and sons, inc. New-York, pp20-35.

Anonyme (1978). www.parc.national.de-taï.org/fr/arbre fr.htm.

Bouchet, P (1984). Les plantes d'usage traditionnel à propriété antifongiques. Pharm. Afr. Noire 20: 10-14.

Burkill, H.M (1985). The Useful plants of West Tropical Africa, Vol.1 (second Ed) Royal Botanic Gardens, Kew, Great Britain, pp 425-426.

Chouvala, S (1984). Les maladies tropicales .Ed. Mir. Moscou 194 p.

Cowan, M.M (1999). Plant products as antimicrobial agents. Clin. Microbiol. Rev. 12: 564-582.

Gentilini, M., Caumes, E., Danis, M., Mouchet, J., Duflo, B., Lagarderr, B., Richard-Lenoble, D., Brucker, G (1993). Nématodes intestinales. In : Médecine-Science (Ed) Médecine tropicale. Flammarion, pp 180-195.

Guédé-Guina, F., Kra, M.A.K., Bonga, M. De Souza, C (1995). Activité antimicrobienne d'un extrait végétal contre les germes opportunistes au cours du SIDA. Rev. Med. Pharm. Afr 9 : 13-19. 
Holt, R (1975). Laboratory test of antifungal drug. J. Clin. Pathol. 28: 767-774.

Hutchings, A., Scott, A.H., Lewis, G., Cunninghan, A.B (1996). Zulu Medicinal Plants, An Inventory. University of Natal Press, Pietermarizburg, South Africa. 450 pp.

Ionela, C.D., Ion, B.I (2007). Plant products as antimicrobial agents. Analele Ştiinţifice ale Universităţii Alexandru Ioan Cuza" Secţiunea Genetică şi Biologie Moleculară VIII: 151-156.

Iwu, M.M., Duncan, R.A., Okunji, O.C (1999). New antimicrobials of plant origin. Reprinted from: perspectives on new crops and new uses. J. Janick (ed.), ASHS Press, Alexandria, VA. 457- 462.

Kameswara Rao, B., Giri, R., Kesavulu, M.M., Apparao, Ch (2000). Effect of oral administration of bark extracts of Pterocarpus santalinus L. on blood glucose level in experimental animals. J. Ethnopharmacol. 74: 69-74.

Kamtchouing, P., Kahpui, S.M., Dzeufiet, P.D., T'edong, L., Asongalem, E.A., Dimoa, T (2006). Anti-diabetic activity of methanol/methylene chloride stem bark extracts of Terminalia superba and Canarium schweinfurthii on streptozotocin-induced diabetic rats. J. Ethnopharmacol. 104: 306-309.

Laurent, F., Sapin, V., Vincent, C.M., Campagni, H.P (1992). Les Aspergilloses. Lyon pharmaceutique 43: 339-349.

McGaw, J. L., Rabe, T., Sparg, S.G., Jäger, A.K., Eloff, J.N., Van Staden, J (2001). An investigation of the biological activity of Combretum species. J. Ethnopharmacol, 75: 45-50.

Pechere, J. C. (1970). Reconnaître, comprendre, traiter les infections Edisem.Inc. Ed. Maloine 37: 446-448.

Van Wyk, B.E., Van Oudtshoorn, B., Gericke, N (1997). Medicinal Plants of South Africa Briza Publications, Pretoria, South Africa, $304 \mathrm{p}$.

Zirihi, G.N., Kra, M.A.K., Guédé-Guina, F (2003). Evaluation de l'activité antifongique de Microglossa pyrifolia (LAMARCK) O. KUNZE (Asteraceae) PYMI sur la croissance in vitro de Candida albicans. Rev. Med. Pharm. Afr. 17: 11-18. 